\title{
Análise da efetividade do Ensino Médio com mediação tecnológica no estado de Rondônia
}

\author{
Analysis of the technology mediated High School \\ effectiveness in the state of Rondônia

\section{Análisis de la efctividad de la Enseñanza Media con mediación tecnológica en el estado de Rondônia}

Samuel dos Santos Junio'

https://orcid.org/0000-0003-I500-4939

Jenerson Queiroz Lima Duarte²

https://orcid.org/0000-000I-5653-3672

Lady Day Pereira de Souza ${ }^{3}$

https://orcid.org/0000-0003-1709-8609

Resumo: O presente estudo tem como objetivo analisar a efetividade do programa Ensino Médio com Mediação Tecnológica (EMMTEC) no Estado de Rondônia no período de 2016 a 2018. O referencial teórico que embasa o estudo traz temas como a legislação que institui o ensino médio, o projeto do Ensino Médio com Mediação Tecnológica e a operacionalização do projeto. Os procedimentos metodológicos adotados foram a análise documental dos relatórios e dos documentos oficiais, principalmente a pesquisa realizada por um determinado

\footnotetext{
' Doutorando em Ciências da Educação - Universidade de Trás-os-Montes e Alto Douro - UTAD - Portugal. Professor efetivo do Instituto Federal de Educação Ciência e Tecnologia de Rondônia campus Porto Velho Zona Norte. Pesquisador do Grupo de Pesquisa em Educação a Distância - GEPED e Grupo de Estudos e Pesquisa em Inovação e Sustentabilidade da Amazônia - GEPISA. E-mail: samuel.santos@ifro.edu.br

${ }^{2}$ Especialista em Planejamento Estratégico na Gestão Pública pelo Instituto Federal de Educação Ciência e Tecnologia de Rondônia, Brasil(2019). Assessor Técnico do Ministério Público do Estado de Rondônia. Atua no Ministério Público do Estado de Rondônia. Membro do Grupo de Estudos e Pesquisa em Inovação e Sustentabilidade da Amazônia - GEPISA. E-mail: duarte_jemerson@hotmail.com

${ }^{3}$ Mestre em Desenvolvimento Regional e Meio Ambiente pela Universidade Federal de Rondônia. Professora do Ensino Básico, Técnico e Tecnológico do Instituto Federal de Educação, Ciência e Tecnologia de Rondônia. Pesquisadora do Grupo de Pesquisa em Educação a Distância - GPED e do Grupo de Estudo e Pesquisa em Inovação e Sustentabilidade da Amazônia - GEPISA. E-mail: lady.souza@ifro.edu.br
}

Olhar de professor, Ponta Grossa, v. 24, p. I-2I, e-I5I48.003, 202 I. 
órgão de controle do Estado de Rondônia. Os resultados indicam que o EMMTEC contribuiu para o aumento das matrículas da população de 15 a 17 anos, pois consegue atingir as comunidades de difícil acesso que antes não possuíam todos os professores dos componentes curriculares. A efetividade do EMMTEC se constitui na sua contribuição para a universalização do ensino médio e para o aumento das matrículas nos cursos técnicos concomitantes ao ensino médio.

Palavras-chave: Política educacional. Ensino médio. Mediação Tecnológica. Rondônia. Tecnologia Educativa.

Abstract: This study aims to analyze the effectiveness of the Technology Mediated High School program (EMMTEC, Brazilian acronym) in the State of Rondônia in the period from 2016 to 2018. The theoretical framework that supports the study includes themes such as the legislation that institutes high school, the Technology Mediated High School project and the project operationalization. The methodological procedures adopted were the documentary analysis of reports and official documents, mainly the research carried out by a specific control agency in the State of Rondônia. The results indicate that the EMMTEC contributed to the increase in enrollments for the population aged 15 to 17 , since it manages to reach communities that are difficult to access, which previously did not have all teachers of the curriculum components. The EMMTEC effectiveness is its contribution to the universalization of high school and to the increase in enrollments in technical courses concurrent with high school.

Keywords: Educational policy. High school. Technological Mediation. Rondônia. Educational Technology.

Resumen: Este estudio tiene como objetivo analizar la efectividad del programa de Enseñaza Media con Mediación Tecnológica (EMMTEC) en el Estado de Rondônia en el período de 2016 a 2018 . El marco teórico que sustenta el estudio trae temas como la legislación que instituye la eseñanza media, el proyecto de Enseãnza con Mediación Tecnológica y su puesta en funcionamiento. Los procedimientos metodológicos adoptados fueron el análisis documental de informes y documentos oficiales, principalmente la investigación realizada por un organismo de control específico en el Estado de Rondônia. Los resultados indican que la EMMTEC contribuyó al aumento de las matrículas de la población de 15 a 17 años, ya que logra llegar a comunidades de difícil acceso, que antes no contaban con todos los docentes de los componentes curriculares. La efectividad de la EMMTEC radica en su contribución a la universalización de la escuela secundaria y al aumento de las inscripciones en cursos técnicos simultáneos a la escuela secundaria.

Palabras-clave: Política educativa. Escuela secundaria. Mediación tecnológica. Rondônia. Tecnologia Educacional.

\section{Introdução}

O Estado de Rondônia possui diversas características territoriais, culturais e geográficas que podem influenciar na oferta do ensino e na demanda escolar. Conforme os estudos do Instituto Brasileiro de Geografia e Estatística (IBGE, 2019), o Estado de Rondônia possui a população estimada em I.777,255 habitantes, 73,22\% dessa população residem em área urbana e 26,78\%, em área rural. Além disso, Rondônia é o $13^{\circ}$ estado do país com maior extensão territorial, sendo ainda o terceiro estado mais populoso da Região Norte, superado apenas pelo Pará e pelo Amazonas.

O Estado possui diversos distritos, reservas extrativistas, assentamentos de reforma agrária e comunidades indígenas que vivem às margens dos rios e por todo o seu território, e, sendo assim, muitas localidades tornam-se de difícil acesso, o que influencia diretamente na oferta do ensino médio para um percentual razoável da população (AGUIAR, 2018). Aguiar (2018) afirma que a extensão territorial é recortada por vários rios, furos e igarapés, e muitos alunos residem nas cabeceiras e

Olhar de professor, Ponta Grossa, v. 24, p. I-20, e-15148.003, 202 I.

Disponível em https://revistas2.uepg.br/index.php/olhardeprofessor 
Samuel dos Santos Junio, Jenerson Queiroz Lima Duarte e Lady Day Pereira de Souza

margens dos rios, utilizando-se deles como via de transporte para chegar às escolas. Além disso, a autora cita as estradas sem pavimentação, os atoleiros nas épocas de chuva (que duram de dezembro a março), áreas alagadas, grandes extensões de terras destinadas a reservas com muitas dificuldades de locomoção e acesso.

Tais obstáculos, somados aos problemas com infraestruturas das estradas vicinais, extensão geográfica e transporte escolar, dificultam ou, até mesmo, impossibilitam a oferta educacional do Ensino Médio Presencial no Estado (AGUIAR, 2018). Nesse contexto, questionamos como o programa do Ensino Médio com a Mediação Tecnológica (EMMTEC) no Estado de Rondônia é percebido pelo público-alvo, e se ele ajuda o Estado a atingir as metas fixadas pelo Plano Nacional de Educação (PNE).

Dessa forma, o objetivo central deste estudo é analisar a efetividade do EMMTEC no Estado de Rondônia no período de 2016 a 2018, por meio do apontamento dos principais elementos característicos da execução do programa de ensino médio mediado pela tecnologia. A pesquisa analisa os resultados dos relatórios produzidos pelo Centro de Apoio Operacional de Defesa dos Usuários dos Serviços de Educação (CAOP Educação), que, por meio de estudo, levantou a percepção dos estudantes em relação ao Ensino Médio com Mediação Tecnológica. Com esses dados, foi possível estabelecer a discussão sobre a modalidade de educação a distância como fator estratégico para o governo para implementar as políticas educacionais no estado.

\section{Características da implementação do Ensino Médio com mediação tecnológica em}

\section{Rondônia}

A competência comum da União, dos Estados, do Distrito Federal e dos Municípios estabelecidos na Constituição Federal de 1988, art. 23 inciso V, é proporcionar os meios de acesso à cultura, à educação, à ciência, à Tecnologia, à pesquisa e à inovação. A educação básica é obrigatória e gratuita às pessoas que possuem entre 4 e 17 anos de idade, assegurando inclusive sua oferta gratuita para todos os que a ela não tiveram o acesso na idade própria (BRASIL, 1988). A Lei de Diretrizes e Bases da Educação Nacional (LDB) n 9.394, de 20 de dezembro de 1996, no art. 10, inciso VI, atribui a obrigatoriedade ao Estado de assegurar o ensino fundamental e oferecer prioritariamente o ensino médio. Quanto à relação da educação profissional técnica com o nível médio, o art. 36-B dispõe que o ensino médio pode ser desenvolvido junto com o ensino técnico (BRASIL, 2005b).

Com o objetivo de elucidar de forma sintética as atribuições da União, Estados e Municípios, foi instituido o Plano Nacional de Educação (PNE), considerado um marco fundamental para a política pública educacional no âmbito nacional. O PNE foi aprovado pela Lei $n^{\circ} 13.005$ de 2014 (BRASIL,

Olhar de professor, Ponta Grossa, v. 24, p. I-20, e-I5I48.003, 2021. 
2014), e tem como objetivo a consolidação de um sistema capaz de concretizar o direito à educação, em sua integralidade, dissolvendo as barreiras para o acesso e permanência, reduzindo as desigualdades, promovendo os direitos humanos e garantindo a formação para o trabalho e para o exercício autônomo da cidadania (BRASIL, 20I5).

Segundo Costa e Oliveira (20/3), o PNE é um instrumento decisivo e estratégico para a educação brasileira, já que estabelece diretrizes e metas a serem alcançadas até 2020. Cada meta vem acompanhada de estratégias que visam atingir os objetivos propostos, sendo composto por 10 diretrizes e 20 metas. Como diretrizes, o plano apresenta: I) Erradicação do analfabetismo; 2) Universalização do atendimento escolar; 3) Superação das desigualdades educacionais; 4) Melhoria da qualidade de ensino; 5) Formação para o trabalho; 6) Promoção da sustentabilidade socioambiental; 7) Promoção humanística, científica e tecnológica do país; 8) Estabelecimento de meta de aplicação de recursos públicos em educação como proporção do produto interno bruto; 9) Valorização dos profissionais da educação; 10) Difusão dos princípios da equidade, do respeito à diversidade e a gestão democrática da educação (BRASIL, 20I5).

Tratando do ensino médio, a Meta II do PNE tem como objetivo triplicar o número de matrículas da educação profissional técnica de nível médio, garantindo a qualidade da oferta e a expansão em, no mínimo, 50\% dessa modalidade no segmento público (BRASIL, 20I5). Essa ampliação do número de matrículas na educação profissional possibilita o acesso à formação, em especial para a população mais pobre, contribuindo, assim, para a redução das desigualdades sociais no Brasil, conforme a própria LDB propõe quando trata da preparação do educando para o exercício das profissões técnicas, sem prejuízo da sua formação geral (BRASIL, 20I5).

O Estado de Rondônia, em seu Plano Estratégico de 2013-2018, trouxe como projeto prioritário o Ensino Médio Inovador. Mediado por meio da tecnologia, o projeto buscava $\circ$ fortalecimento do ensino médio. Essa política pública foi reafirmada no Plano Estratégico de 20162020 , no eixo de bem-estar social, tendo como uma das metas a redução da evasão escolar em $25 \%$, no âmbito do ensino médio até 2018 (RONDÔNIA, 2016).

O Governo do Estado adota a educação a distância como modalidade para o ensino médio, respaldando-se na Lei de Diretrizes e Bases da Educação, que prevê o incentivo aos Programas de Ensino a Distância $(\mathrm{EaD})$, em todos os níveis e modalidades de ensino, e de educação continuada. De forma complementar, o Decreto 5.622/2005 contempla que:

Art. $I^{\circ}$. Para os fins do decreto, caracteriza-se a educação à distância como modalidade educacional na qual a medida didático-pedagógica nos processos de ensino e aprendizagem ocorre com a utilização de meios e tecnologias de informação e comunicação, com estudantes e professores desenvolvendo atividades educativas em lugares ou tempos diversos (BRASIL, 2005a).

Olhar de professor, Ponta Grossa, v. 24, p. I-20, e-|5|48.003, 202 I. 
Samuel dos Santos Junio, Jenerson Queiroz Lima Duarte e Lady Day Pereira de Souza

Além disso, o mesmo Decreto prevê que a educação a distância pode ser ofertada em diversos níveis, principalmente na educação profissional, especificamente voltada para cursos técnicos de nível médio (BRASIL, 2005a).

Partindo dessas bases legais, o Projeto de Ensino Médio com Mediação Tecnológica (EMMTEC) entrou em vigor no Estado de Rondônia em 2016, nas escolas da rede pública do estado, tendo como objetivo universalizar o acesso à última etapa da educação básica (GERMANO; ZUIN, 20I8). Segundo a Lei $n^{\circ}$ 3.846/2016 (RONDÔNIA, 2016), o Projeto Ensino Médio com Mediação Tecnológica tem como objetivo a implantação do Ensino Médio com Mediação Tecnológica aos estudantes que residem na zona rural, cujas localidades são de difícil acesso, com demanda reprimida ou em localidades onde houver carência de profissionais.

Assim, o projeto oferta o ensino médio técnico regular com o uso de ferramentas tecnológicas, sendo composto por aulas transmitidas via satélite, em tempo real, as quais são disponibilizadas posteriormente no banco de aulas, além de garantir aulas interativas, em que os alunos possuem ferramentas de comunicação e interação com o professor, como o chat (RONDÔNIA, 2016).

Aguiar (2018) afirma que um dos problemas abordados pelo Estado, e que justifica a realização desse projeto, é a falta de professores habilitados em alguns dos componentes curriculares do ensino médio. Entretanto, a realidade é que a quantidade de inscritos para os cargos não preenchem as vagas dos certames elaborados, sendo a situação mais crítica a de Matemática, o que reafirma a necessidade de novas atitudes, métodos e posturas.

Portanto, a implementação do Ensino Médio com Mediação Tecnológica avançou no contexto educacional dos municípios, pelo fato de proporcionar acesso e permanência dos alunos do ensino médio em sua localidade de origem. Outro ponto que merece destaque é a proposta de redução do custo da educação, já que o Estado propôs, em 2016, a substituição de 712 professores presenciais por 8 professores na modalidade à distância, sendo esta uma política de barateamento da educação (AGUIAR, 20I8).

\section{Modalidade EaD como fator estratégico na execução das políticas educacionais em Rondônia}

Segundo o Ministério da Educação (BRASIL, 2008), a educação é um assunto estratégico ao país e constitui fator relevante de sucesso, sendo imprescindível a definição do regime de colaboração, que significa o compartilhamento de competências políticas, técnicas e financeiras para a execução de programas de manutenção e desenvolvimento da educação. Desse modo, requer uma atuação entre

Olhar de professor, Ponta Grossa, v. 24, p. I-20, e-15|48.003, 2021.

Disponível em https://revistas2.uepg.br/index.php/olhardeprofessor 
os entes federados, sem ferir-lhes a autonomia, garantindo o direito à educação de qualidade para todos. A escolha da modalidade de oferta pode ser considerada uma estratégia caso as ações políticas tenham compatibilidade com as necessidades regionais.

Nesse sentido, de acordo com Santos (20I2), a EaD vem sendo utilizada em larga escala no contexto das políticas educacionais e considerada uma estratégia, já que atinge um grande quantitativo de pessoas e reduz os custos com a educação. Nessa perspectiva, o campo das políticas educacionais, a conjuntura política e tecnológica, tem se mostrado cada vez mais favorável à implementação da EaD. Esse contexto colabora para que a modalidade ocupe uma posição instrumentalmente estratégica capaz de diminuir os déficits do sistema, ampliar o acesso da população com vulnerabilidade social e geográfica à educação, democratizar o ensino e reduzir os custos nas áreas de serviços educacionais. Assim, Santos (2012) considera a EaD uma das ferramentas mais importantes para implementar o sistema educacional na atualidade.

Portanto, é possível afirmar que as políticas públicas para a educação a distância são ações governamentais que podem permitir ao cidadão acesso à educação de qualidade para todos, fazendo com que a responsabilidade pela formação do aluno seja do poder público. Com base nessa concepção, torna-se importante ressaltar que as políticas públicas voltadas para a $\mathrm{EaD}$ visam a universalização do ensino, ou seja, levar o ensino às mais diversas regiões geográficas, contemplando inclusive os alunos que moram em áreas de difícil acesso. Contudo, para implementar esse e qualquer outro componente de gestão, as organizações públicas devem estar atentas aos elementos de gestão que podem refletir em qualidade na estratégia adotada.

Segundo Sano e Filho (20 I3), a Lei n I I.653/2008 estabeleceu que a gestão do Plano Plurianual de 2008 a 201 I observará os princípios de eficiência, eficácia e efetividade na avaliação dos programas, sendo estes elementos importantes para a qualidade nas atividades da Gestão Pública. Dessa forma, a avaliação dos programas ocorre em três etapas, sendo a primeira a avaliação das metas (eficácia); a segunda, avaliação de impacto (efetividade) e, por fim, a avaliação do processo (eficiência), conforme a Figura I.

Figura I - Fluxograma da avaliação

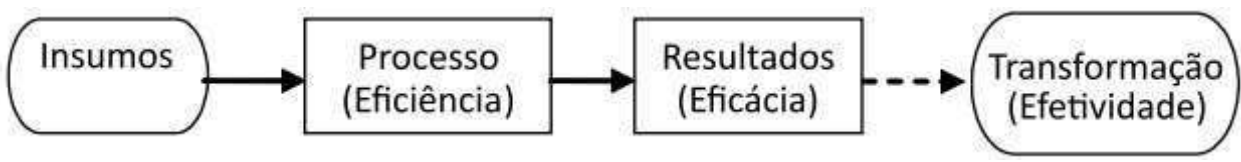

Fonte: Sano e Filho, 2013.

A efetividade está relacionada ao impacto social, que procura identificar os efeitos produzidos sobre uma população-alvo de um programa social. Quando se trata de avaliar um programa social, é

Olhar de professor, Ponta Grossa, v. 24, p. I-20, e-I5I48.003, 202 I. 
Samuel dos Santos Junio, Jenerson Queiroz Lima Duarte e Lady Day Pereira de Souza

imprescindivel considerar o real valor de um investimento social (SANO; FILHO, 20I3). Portanto, importa identificar qual o impacto e os efeitos do projeto de ensino médio com mediação tecnológica para o público-alvo, bem como para a gestão pública.

Conforme a Portaria Interministerial publicada pelo Ministério da Educação, tratando da qualidade da educação (BRASIL, 2008), a qualidade da educação depende menos das estruturas e dos sistemas de ensino que da unidade escolar e da sua autonomia pedagógica, administrativa e financeira. Além disso, é importante que as políticas públicas promovam o fortalecimento da liberdade na educação e o controle social que promova a igualdade de direitos para a população.

O Ministério da Educação (BRASIL, 2008) afirma que é necessário, pelo menos, um valor mínimo de $R \$ 2.000$ por aluno/ano para que haja uma educação de qualidade. Porém, atualmente, as escolas estaduais de ensino médio investem aproximadamente um valor de $\mathrm{R} \$ 1.000$ por aluno/ano. Com ○ Fundo de Manutenção e Desenvolvimento da Educação Básica e de Valorização dos Profissionais da Educação (FUNDEB), essa estimativa fica em torno de R $\$ 1.400$ por aluno/ano. Além disso, outra questão que influencia de forma direta a universalização do ensino é o impedimento legal dos Estados de contratação de serviços públicos devido aos limites da Lei de Responsabilidade Fiscal. Conforme o art. 19 desta lei, a despesa total com pessoal, em cada período de apuração e em cada ente da Federação, não poderá exceder os percentuais de receita corrente líquida, cujos percentuais são de $50 \%$ para a União e $60 \%$ para Estados e Municípios, o que impede a expansão do atendimento educacional, através da contratação de educadores (BRASIL, 2000).

Além disso, dados financeiros sobre o gasto com educação no Estado de Rondônia apontam que, entre os anos de 2016 a 2019, os montantes dos recursos para o ensino médio técnico foram variantes. Em 2016 e 2017, os montantes destinados foram crescentes. Uma das razões para isso foi o aumento do quantitativo de matrículas. Já em 2018 e 2019, houve um decréscimo nos valores destinados, conforme o Quadro I, a seguir. Um dos motivos possíveis desse decréscimo seria a não abertura de mais polos (RONDÔNIA, 2019b).

Quadro I - Recursos destinados para o Ensino Profissional em Rondônia (2016-2019)

\begin{tabular}{|c|c|c|c|c|}
\hline & 2016 & 2017 & 2018 & 2019 \\
\hline Valor (R\$) & $948.58 I, 00$ & $1.574 .706,00$ & $716.914,00$ & $1.000 .000,00$ \\
\hline
\end{tabular}

Fonte: Adaptado SEPOG, 2019.

É importante ressaltar que, na estrutura da Lei Orçamentária Anual, não há diferenciação de valores destinados para a educação presencial e a distância. Na estrutura da lei, o ensino é divido em ensino fundamental, médio, profissional, educação para jovens e adultos e educação especial. Assim, a

Olhar de professor, Ponta Grossa, v. 24, p. I-20, e-15I48.003, 2021. 
ação prevê a manutenção e a ampliação das políticas públicas para o desenvolvimento da Educação Profissional Técnica em Nível Médio.

Dessa forma, como afirma o Ministério da Educação (BRASIL, 2008), as políticas públicas para o ensino médio devem ter como principal objetivo o compromisso com a universalização do ensino, tendo o Estado o dever de garantir a progressiva extensão da obrigatoriedade e da gratuidade nessa etapa da educação.

Como modo de cumprir esse objetivo, o Estado de Rondônia propôs a implementação e a operacionalização do projeto do Ensino Médio com Mediação Tecnológica (EMMTEC), a fim de também atender a meta número 3 do Plano Nacional de Educação, que consiste em universalizar, até 2016, o atendimento escolar para toda a população de 15 a 17 anos e elevar, até o final do período de vigência do PNE, a taxa líquida de matrículas no ensino médio para $85 \%$.

\section{Operacionalização do Ensino Médio com mediação tecnológica em Rondônia}

Para a implementação do Ensino Médio com Mediação Tecnológica, o Governo do Estado de Rondônia, por meio da Gerência do Centro de Mídias - GCM da Secretaria de Educação, operacionalizou todo o sistema, com o objetivo de realizar a assessoria pedagógica. A assessoria contemplou o envio de material didático pedagógico para os professores ministrantes presenciais, bem como ofereceu o suporte técnico e administrativo e promoveu as formações continuadas dos professores e coordenadores de projetos, nas 18 regionais do Estado (AGUIAR, 2018).

Segundo Aguiar (2018), esse modelo da EaD no nível médio conta com aulas transmitidas em tempo real, diariamente, de forma simultânea e em horário regular para todas as salas nas escolas sede que fazem parte do projeto. Para isso, a tecnologia utilizada é por via satélite e IP multimídia, possibilitando a interação entre os professores ministrantes, professores presenciais e estudantes da rede, conforme a Figura 2 .

Olhar de professor, Ponta Grossa, v. 24, p. I-20, e-15I48.003, 202 I. 
Figura 2 - Operacionalização do Ensino Médio com mediação tecnológica em Rondônia

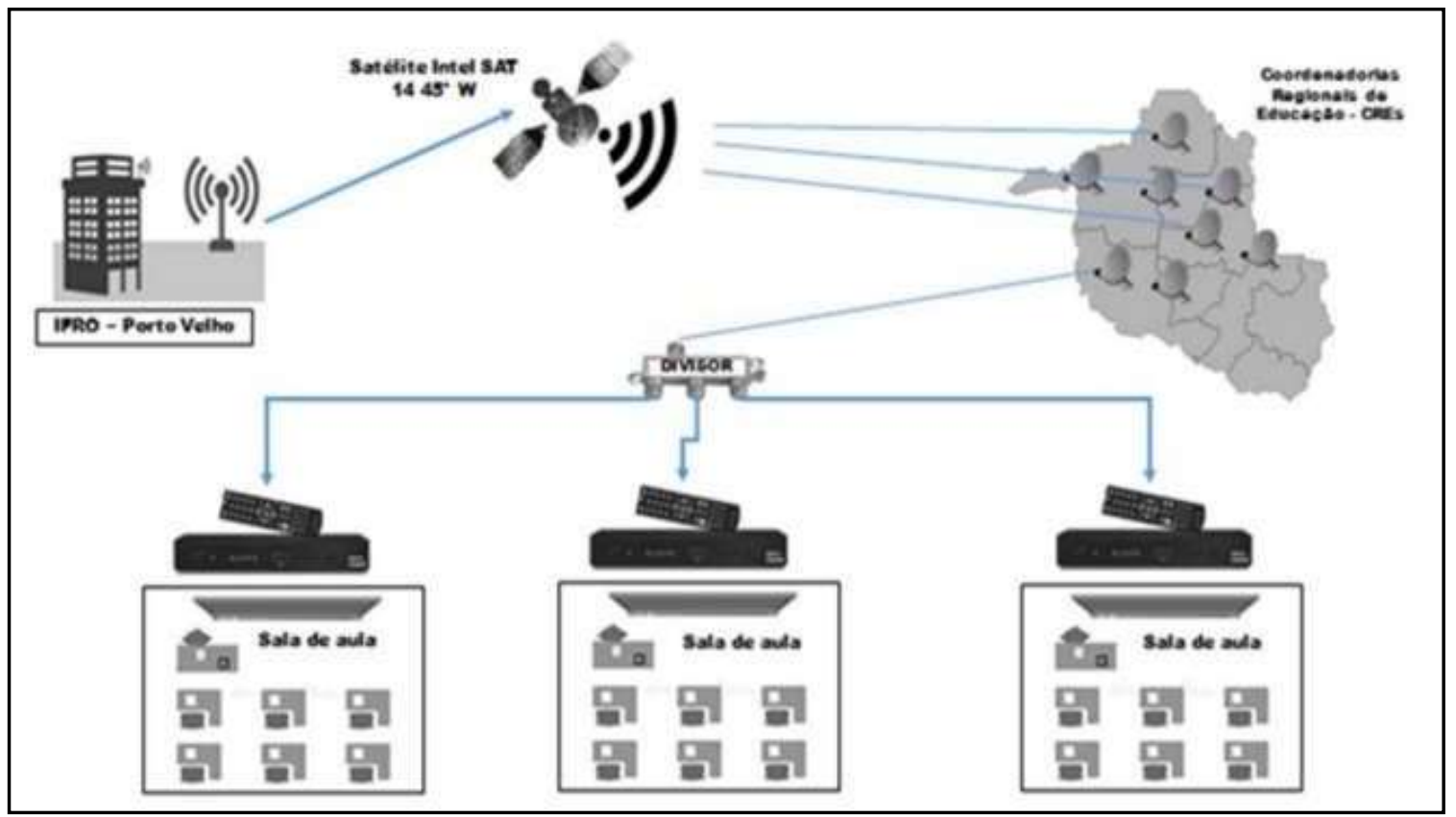

Fonte: Aguiar, 2018.

O projeto é composto por 26 professores ministrantes e 276 professores presenciais. Além deles, a equipe é formada por uma Assessoria Pedagógica de Estúdio, que torna o processo viável, através da estrutura ilustrada. Nessa proposta, temos como atores a Gerência do Centro de Mídias, que conta com uma Coordenação Geral, além de Professores Ministrantes, responsáveis por todos os instrumentais necessários, como também o Coordenador Pedagógico Regional de Ensino, professores presenciais, Coordenação Pedagógica de Estúdio e Coordenação Pedagógica da Secretaria de Educação do Estado, apresentados na Figura 3.

Figura 3 - Organograma do Centro de Mídias de Rondônia

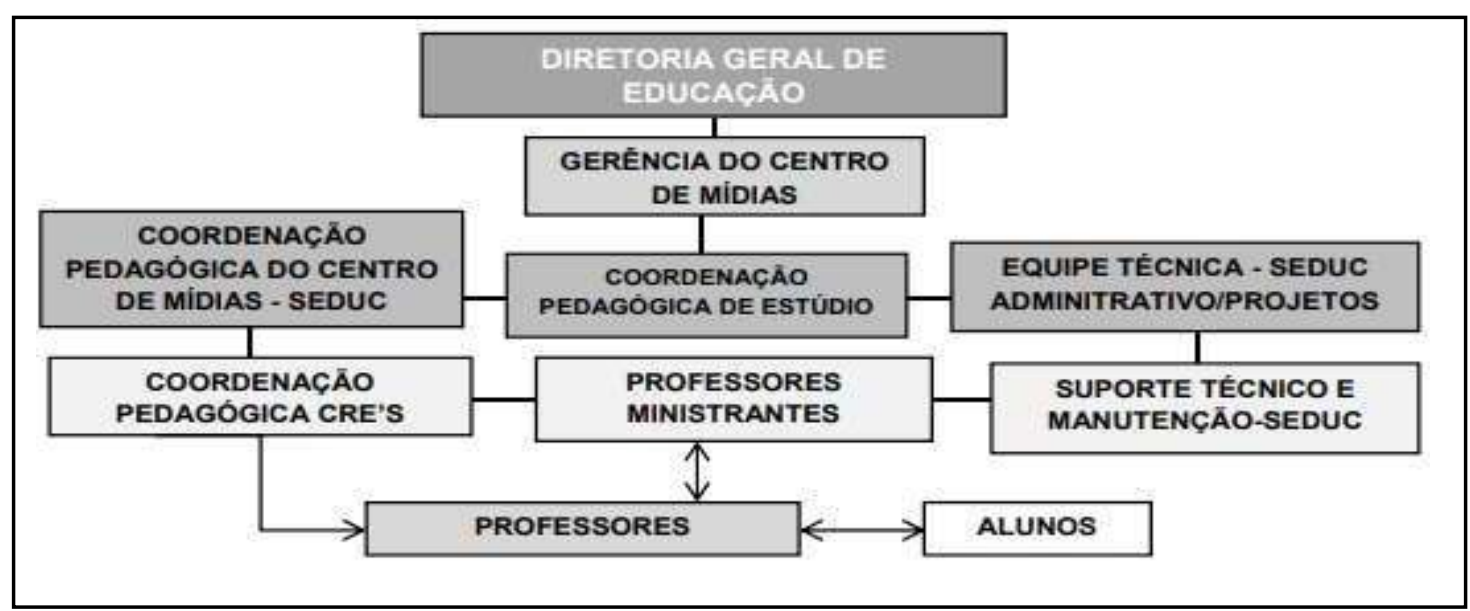

Fonte: Aguiar, 2018.

Olhar de professor, Ponta Grossa, v. 24, p. I-20, e-I5I48.003, 202 I.

Disponível em https://revistas2.uepg.br/index.php/olhardeprofessor 
Segundo Aguiar (2018), a Gerência do Centro de Mídias conta com a seguinte equipe: Coordenação Pedagógica da SEDUC/RO: acompanha e orienta os Professores Ministrantes no Plano Didático Pedagógico e providencia formação continuada aos Professores Presenciais; Coordenação Pedagógica Regional de Ensino (CRE): responsável pela solicitação da instalação e manutenção dos kits tecnológicos, composto por antenas, receptores, computador, impressora e televisor. Também é responsabilidade dessa coordenação buscar soluções para suas demandas e problemas nos equipamentos, além de oferecer orientação e assistência pedagógica ao Professor Presencial; Coordenação Pedagógica de Estúdio: acompanha e orienta os Professores Ministrantes nas adequações necessárias, bem como no envio de materiais e inserção das teleaulas no YouTube; Professores ministrantes: responsáveis pela preparação do Plano de Aula, Plano Didático Pedagógico, Cronograma de Sequência de aulas, Plano Instrucional, Atividades Extraclasse, Plano de Teleaulas e Recuperação, dentre outros instrumentais; Professores Presenciais: responsáveis pelo manuseio tecnológico e pela realização da mediação do Plano Didático Pedagógico em sala; Equipe de Suporte Técnico: responsável pela manutenção, instalação e remoção dos equipamentos.

Tendo em vista a complexidade do projeto e seu impacto na sociedade, o Ministério Público do Estado de Rondônia, através do Centro de Apoio da Educação, realiza o acompanhamento da implantação e implementação do Projeto do Ensino Médio com Mediação Tecnológica (EMMTEC).

\section{Centro de apoio operacional de defesa dos usuários dos serviços de educação - CAOP}

\section{Educação}

O Centro de Apoio Operacional de Defesa dos Usuários dos Serviços de Educação (CAOP Educação) é um órgão auxiliar da atividade funcional do Ministério Público, destinado a oferecer suporte e apoio técnico-jurídico aos órgãos de execução, na defesa do direito à educação (RONDÔNIA, 20I9a).

O CAOP possui diversas atribuições, mas compete-lhe, em suma:

I. Promover a articulação, integração e intercâmbio entre os órgãos de execução, inclusive para efeito de atuação conjunta ou simultânea, quando cabível; II. Apresentar sugestões visando estabelecer política institucional para a atuação dos órgãos de execução correspondentes às respectivas áreas de educação, inclusive no que concerne à estrutura e a programas específicos;

III. Acompanhar a política nacional e estadual referentes à educação, realizando estudos e oferecendo sugestões às entidades públicas e privadas com atribuições no setor;

IV. Representar o Ministério Público, quando cabível e por delegação do Procurador Geral de Justiça, junto aos órgãos que atuam na educação;

V. Prestar auxílio aos órgãos de execução do Ministério Público, por sua

Olhar de professor, Ponta Grossa, v. 24, p. I-20, e-I5I48.003, 202 I.

Disponível em https://revistas2.uepg.br/index.php/olhardeprofessor 
Samuel dos Santos Junio, Jenerson Queiroz Lima Duarte e Lady Day Pereira de Souza

solicitação, na instrução de procedimentos da educação;

VI. Elaborar e implementar os planos, programas e projetos na área de educação, em conformidade com as diretrizes institucionais fixadas;

VII. Desenvolver estudos e pesquisas, criando ou sugerindo a criação de grupos e comissões de trabalho, dentre outras (RONDÔNIA, 2020).

Sendo assim, o CAOP Educação realizou um estudo, no período de junho de 2016 a novembro de 2017, com o objetivo de coletar dados para verificar o funcionamento e a qualidade do Ensino Médio Técnico com Mediação Tecnológica, através de visitas in loco nas escolas que oferecem essa modalidade de ensino.

Tal estudo proporcionou o diálogo com os alunos, com os professores, com os gestores e com a comunidade, a fim de entender a realidade e produzir relatório. Ao final do estudo, o CAOP propôs sugestões e recomendações de melhorias à Secretaria de Educação do Estado de Rondônia, a fim de fazer cumprir o disposto na LDB e no PNE sobre a universalização e a melhoria do ensino médio. Neste estudo, utilizaremos os dados dessa pesquisa para analisar a efetividade da Mediação Tecnológica no Estado de Rondônia.

\section{Metodologia}

Este estudo se desenvolve a partir do método indutivo de pesquisa, utilizando técnicas de observação sistemática dos fatos, ou seja, o fluxo de processos e operações do projeto de ensino médio com mediação tecnológica e seus gargalos, para que seja possível propor soluções ao caso (GERHARDT; SILVEIRA, 2009). Os objetivos da pesquisa assumem caráter exploratório e descritivo. Segundo Gil (2002), os objetivos que possuem tal caráter descrevem, com maior familiaridade, os elementos gerenciais e estratégicos do projeto de ensino médio com mediação tecnológica, apresentando suas variáveis, a fim de torná-lo mais explícito, além de descrever os fatos que ocorrem na organização, demonstrando-os de forma clara.

Esta também é uma pesquisa bibliográfica, pois busca o esclarecimento e definição de conceitos e perspectivas teóricas que sustentam e formam o referencial teórico. Gil conceitua a pesquisa bibliográfica como a "pesquisa desenvolvida com base em material já elaborado, constituído principalmente de livros e artigos científicos” (GIL, 2002, p. 44). Para a construção da pesquisa bibliográfica, os principais temas abordados foram: legislação nacional da educação, educação a distância como fator estratégico e operacionalização do projeto de ensino médio técnico com mediação tecnológica.

Para alcançar o objetivo do estudo, foi realizada análise documental, nos documentos, nos relatórios e nos registros produzidos pelo CAOP educação, com o objetivo de verificar a efetividade

Olhar de professor, Ponta Grossa, v. 24, p. I-20, e-15I48.003, 2021.

Disponível em https://revistas2.uepg.br/index.php/olhardeprofessor 
dessa modalidade de ensino, bem como discutir sobre a modalidade de educação a distância como fator estratégico para o governo.

\section{Resultados e discussões}

De acordo com o plano Estadual de Educação - PEE/RO: 2014 a 2024 (RONDÔNIA, 20I4, p. 42), a população de jovens na faixa etária entre 15 e 17 anos em Rondônia é de 95.929 pessoas, das quais 44.292 jovens estão matriculados no ensino médio na rede pública. Em percentuais, $54 \%$ dos jovens estão fora dos bancos escolares. Já em 2015, a Rede Estadual de Ensino de Rondônia teve 56.7I2 matrículas, considerando ainda a população mensurada pelo IBGE no censo de 2010, apresentando um déficit de 39.217 jovens fora dos bancos escolares, o que representa $41 \%$ da população em estudo.

O Projeto Ensino Médio com Mediação Tecnológica, no ano de 2018, foi implementado em 18 Coordenadorias Regionais de Ensino (CRE), possuindo 93 turmas em 87 escolas, das quais 44 são municipais, sendo 2 quilombolas e 43 estaduais. $\mathrm{Na}$ Rede Estadual, conta com 43 escolas estaduais, sendo 5 indígenas e I quilombola, que juntas totalizam 2.077 alunos matriculados.

O estudo identificou que o projeto oferece o ensino médio através de módulos, não ofertando material didático de apoio. Além disso, há uma apresentação muito rápida dos conteúdos, o que pode trazer dificuldades na compreensão e, consequentemente, na aprendizagem para os alunos. No ano de 2016, foi identificado que um dos motivos da implantação dessa modalidade de ensino foi a falta de professores em alguns componentes curriculares, além do quantitativo de professores readaptados, conforme Quadro 2.

Quadro 2 - Necessidade de Professor - 2017

(Continua)

\begin{tabular}{|c|c|c|c|c|}
\hline \multirow{2}{*}{$\mathbf{N}^{\circ}$} & MUNICIPIO & \multicolumn{2}{c|}{ CARGA HORÁRIA } & \multirow{2}{*}{$\begin{array}{c}\text { TOTAL } \\
\text { GERAL }\end{array}$} \\
\cline { 2 - 4 } & $\begin{array}{c}\text { Coordenadoria } \\
\text { Regional de Ensino }\end{array}$ & $\mathbf{4 0 h}$ & $\mathbf{2 0 h}$ & \\
\hline 01 & $\begin{array}{c}\text { Alta Floresta Do } \\
\text { Oeste }\end{array}$ & 05 & 06 & 11 \\
\hline 02 & Ariquemes & 19 & 05 & $\mathbf{2 4}$ \\
\hline 03 & Buritis & 13 & 05 & 18 \\
\hline 04 & Cacoal & $* 1$ & $*$ & $*$ \\
\hline
\end{tabular}

Fonte: Adaptado de CAOP EDUCAÇÃO, 2018.

Olhar de professor, Ponta Grossa, v. 24, p. I-20, e-I5I48.003, 2021. 
Samuel dos Santos Junio, Jenerson Queiroz Lima Duarte e Lady Day Pereira de Souza

Quadro 2 - Necessidade de Professor - 2017

(Conclusão)

\begin{tabular}{|c|c|c|c|c|}
\hline 05 & Cerejeiras & 03 & 04 & 07 \\
\hline 06 & Costa Marques & 00 & 02 & 02 \\
\hline 07 & Espigão Do Oeste & 08 & 02 & 10 \\
\hline 08 & Extrema & 06 & 04 & 10 \\
\hline 09 & Guajará-Mirim & 27 & 02 & 29 \\
\hline 10 & Jaru & 06 & 05 & 11 \\
\hline 11 & Ji-Paraná & 52 & 05 & 57 \\
\hline 12 & Machadinho do Oeste & 39 & 01 & 40 \\
\hline 13 & Ouro Preto do Oeste & 01 & 01 & 02 \\
\hline 14 & Pimenta Bueno & 13 & 03 & 16 \\
\hline 15 & Porto Velho & 63 & $*$ & 63 \\
\hline 16 & Rolim de Moura & 10 & 02 & 12 \\
\hline 17 & $\begin{array}{c}\text { São Francisco do } \\
\text { Guaporé }\end{array}$ & 05 & 06 & 11 \\
\hline 18 & Vilhena & 09 & 03 & 12 \\
\hline
\end{tabular}

Fonte: Adaptado de CAOP EDUCAÇÃO, 2018.

Conforme o Quadro 2, as 5 Coordenadorias Regionais de Ensino do Estado de Rondônia que possuem o maior déficit de professores são: Porto Velho, com 63 docentes de 40 horas semanais; jiParaná, com 57, sendo 52 de 40 horas e 5 de 20 horas; Machadinho do Oeste, com 40 docentes, sendo 39 docentes de 40 horas e apenas I de 20 horas; e Guajará-Mirim, com 29 professores, sendo 27 docentes de 40 horas e 2 de 20 horas.

Já as Coordenadorias Regionais de Ensino do Estado de Rondônia que possuem o menor déficit de docentes foram: Ouro Preto do Oeste, com 2 professores, sendo I de 40 horas e I de 20 horas semanais; Costa Marques, também com 2 professores, ambos de 20 horas; Cerejeiras, com 7, sendo 3 de 40 horas e 4 de 20 horas; Espigão do Oeste, com 10 docentes, sendo 8 de 40 horas e 2 de 20 horas; e Extrema, também com 10 docentes, dos quais 6 são de 40 horas e 4 de 20 horas.

As demais Coordenadorias Regionais de Ensino que não foram citadas entre as que possuem o maior ou menor déficit de professores são aquelas que possuem a carência entre II a 25 docentes. Essa carência de profissionais habilitados poderia ser sanada com a aplicabilidade do projeto somente

Olhar de professor, Ponta Grossa, v. 24, p. I-20, e- I5 I48.003, 202 I. 
no componente curricular específico, conforme a Recomendação N. 00I/20I8 do CAOP Educação (RONDÔNIA, 20I8).

Além do déficit de professores, outra dificuldade enfrentada na oferta do ensino médio é a ausência da internet, pois, mesmo tendo recebido os netbooks, os alunos não possuem internet para utilizá-los. Foram também relatadas deficiências nos materiais de apoio, nas explicações, na metodologia, dentre outros aspectos. Para apurar melhor tais questões, o Ministério Público realizou um estudo em blocos, onde o bloco I e II atuam nos aspectos pedagógicos, o bloco III atua nas questões de infraestrutura, o IV, nas dificuldades encontradas pelos professores, e os blocos $\mathrm{V}$ e $\mathrm{VI}$, nos pontos positivos e negativos, na visão do professor e do aluno.

A primeira análise trata da avaliação do Ensino Médio com a Mediação Tecnológica, na visão dos alunos, conforme Quadro 3.

Quadro 3 - Avaliação do Ensino Médio com Mediação Tecnológica pelos estudantes

\begin{tabular}{|c|c|c|c|c|}
\hline \multirow{2}{*}{ coNCEITO } & \multicolumn{2}{|c|}{ Avaliação Geral EMMTEC } & \multicolumn{2}{c|}{ Avaliação da Aprendizagem } \\
\cline { 2 - 5 } & QUANT. & QUANT. (\%) & QUANT. & QUANT. (\%) \\
\hline Excelente & 78 & $9,3 \%$ & 45 & $5 \%$ \\
\hline Otimo & 178 & $21,2 \%$ & 148 & $18 \%$ \\
\hline Bom & 346 & $41,2 \%$ & 329 & $39 \%$ \\
\hline Regular & 235 & $28 \%$ & 309 & $37 \%$ \\
\hline $\begin{array}{c}\text { Não } \\
\text { responderam }\end{array}$ & 2 & $0,3 \%$ & 8 & $1 \%$ \\
\hline Total & 839 & $100 \%$ & 839 & $100 \%$ \\
\hline
\end{tabular}

Fonte: Adaptado CAOP EDUCAÇÃO, 2018.

Os resultados mostram que a avaliação dos alunos é positiva sobre essa temática, já que a satisfação apresentada é em torno de 71,7\%, somando as classificações de excelente, ótimo e bom. Alves relata que "a Educação a Distância oferece oportunidades que pelo modelo presencial seria difícil ou impossivel de atingir" (ALVES, 20II, p. 9l). A complementar essa ideia, o outro aspecto analisado na pesquisa é como os alunos avaliam a própria aprendizagem nas disciplinas ofertadas no Ensino Médio com a Mediação Tecnológica, a qual demonstrou resultado positivo, já que $62 \%$ dos alunos responderam que a aprendizagem é boa, ótima e excelente. Portanto, os alunos avaliam bem essa modalidade de ensino porque, em circunstâncias de ensino regular, eles não teriam as mesmas possibilidades de aprendizagem, tento em vista a ausência de professoras habilitados em suas comunidades.

Olhar de professor, Ponta Grossa, v. 24, p. I-20, e-15I48.003, 2021. 
Um novo aspecto analisado versa sobre os componentes curriculares que os alunos possuem maior afinidade, conforme o Quadro 4.

Quadro 4 - Afinidades dos componentes curriculares pelos estudantes

\begin{tabular}{|c|c|c|c|}
\hline $\begin{array}{c}\text { Componente } \\
\text { Curriculares }\end{array}$ & Mais gostaram & $\begin{array}{c}\text { Melhor } \\
\text { assimilaram }\end{array}$ & $\begin{array}{c}\text { Mais } \\
\text { sentiram } \\
\text { dificuldades }\end{array}$ \\
\hline Português & 41 & 49 & 77 \\
\hline Matemática & 242 & 202 & 173 \\
\hline História & 141 & 163 & 17 \\
\hline Geografia & 77 & 55 & 22 \\
\hline Biologia & 74 & 57 & 24 \\
\hline Química & 21 & 25 & 252 \\
\hline Física & 24 & 24 & 145 \\
\hline Filosofia & 43 & 45 & 18 \\
\hline Sociologia & 15 & 16 & 8 \\
\hline Inglês & 21 & 29 & 74 \\
\hline Artes & 9 & 15 & 9 \\
\hline NBAZ & 79 & 80 & 10 \\
\hline Ed. Física & 23 & 13 & 0 \\
\hline
\end{tabular}

Fonte: Adaptado CAOP EDUCAÇÃO, 2018.

O Quadro 4 elucida os componentes curriculares que os alunos mais gostaram, melhor assimilaram e os que mais sentiram dificuldades. Como resultado, o componente curricular que os alunos mais gostaram foram os de Matemática, História, Geografia, Noções Básicas de Agroecologia e Zootecnia (NBAZ) e Biologia. Os componentes curriculares que os alunos mais assimilaram foram, novamente, Matemática, História, Geografia, NBAZ e Biologia, evidenciando a relação dos que mais gostaram com os que mais assimilaram.

Os componentes curriculares com que os alunos mais sentiram dificuldades foram os de Química, Física, Inglês, os mesmos que também tiveram o menor quantitativo de respostas nos componentes curriculares dos que mais gostaram e melhor assimilaram.

O Quadro 5 traz resultados sobre o desempenho dos professores, avaliado pelos alunos, e, de modo geral, o resultado foi positivo, já que a maioria das respostas foram os conceitos Bom, Excelente e Ótimo.

Olhar de professor, Ponta Grossa, v. 24, p. I-20, e-15|48.003, 2021. 
Quadro 5 - Desempenho dos professores na percepção dos estudantes

\begin{tabular}{|c|c|c|c|c|c|}
\hline COMPONENTE & EXCELENTE & ÓTIMO & BOM & REGULAR & RUIM \\
\hline Português & 53 & 82 & 163 & 134 & 6 \\
\hline Matemática & 152 & 133 & 129 & 63 & 0 \\
\hline História & 142 & 138 & 143 & 54 & 0 \\
\hline Geografia & 84 & 97 & 165 & 62 & 0 \\
\hline Biologia & 56 & 73 & 127 & 31 & 4 \\
\hline Química & 22 & 47 & 125 & $|6|$ & 4 \\
\hline Física & 21 & 36 & 101 & 63 & 4 \\
\hline Filosofia & 33 & 62 & 169 & 52 & 0 \\
\hline Sociologia & 51 & 67 & 179 & 61 & 2 \\
\hline Inglês & 37 & 69 & 203 & 107 & 2 \\
\hline Artes & 33 & 57 & 128 & 98 & 2 \\
\hline NBAZ & 76 & 81 & 110 & 35 & 0 \\
\hline Ed. Física & 25 & 47 & 126 & 114 & 6 \\
\hline Não responderam & 70 & 48 & 60 & 13 & - \\
\hline
\end{tabular}

Fonte: Adaptado CAOP EDUCAÇÃO, 2018.

Os componentes curriculares que mais apresentaram o conceito Excelente como resposta foram Matemática e História. No aspecto Ótimo, também foram as disciplinas de Matemática e História, junto com Geografia e NBAZ. Os componentes curriculares que os alunos mais avaliaram com o conceito Bom foram Inglês, Sociologia, Filosofia, Geografia e Português. Quanto ao Regular, Química e, novamente, os componentes curriculares de Inglês e Língua Portuguesa.

Outro ponto avaliado na visão dos estudantes foi o material didático utilizado por eles na execução do Ensino Médio com a Mediação Tecnológica. Assim, os resultados mostraram-se positivos, já que a maioria das respostas, $62,7 \%$ dos alunos, afirma que os materiais atendem às necessidades, enquanto apenas $35,5 \%$ contrapõem-se a esse posicionamento, e I,8\% não responderam a essa questão.

Um dos fatores também avaliados pelo CAOP Educação foram os pontos positivos e negativos do projeto. Quanto aos pontos positivos, os alunos elencaram fatores como aprendizagem, certificados, professores, explicação em sala de aula e metodologia, tendo principal destaque os professores dos componentes curriculares e as explicações. Quanto aos pontos negativos, os alunos elencaram diversas dificuldades, sendo as principais: a falta ou o sinal fraco da internet, a falta de material adequado, aulas com explicações e metodologia cansativas, a infraestrutura local pouco eficiente, a falta de netbooks, entre outros.

Olhar de professor, Ponta Grossa, v. 24, p. I-20, e-I5I48.003, 2021. 


\section{Considerações finais}

O presente estudo buscou analisar a efetividade do Ensino Médio com a Mediação Tecnológica no Estado de Rondônia no período de 2016 a 2018, por meio da descrição dos principais elementos característicos da execução ensino médio mediado com a tecnologia, e da verificação dos resultados dos relatórios produzidos pelo CAOP Educação diante do estudo da percepção dos estudantes.

Nessa perspectiva, os principais pontos observados foram: o Ensino Médio com Mediação Tecnológica contribuiu para o aumento das matrículas da população de 15 a 17 anos, pois consegue atingir as comunidades de difícil acesso que antes não possuíam todos os professores dos componentes curriculares. Contribuiu também para o aumento das matrículas na educação profissional técnica de nível médio. Favorece a superação das desigualdades educacionais existente entre o ensino das zonas rural e urbano. O EMMTEC possui excelente adesão dos alunos. A falta ou escassez de alguns elementos base, como internet, infraestrutura, materiais, para a execução plena do Ensino Médio com Mediação Tecnológica.

Pode-se afirmar que o EMMTEC pode ser considerado para o Estado uma importante ferramenta estratégica educacional, pois, através de sua execução, o Estado consegue atingir de forma eficiente e eficaz as legislações que orientam a produção de metas educacionais de característica Nacional ao Estado de Rondônia como o Plano Nacional de Educação e, ainda, cumprir os dispositivos legais aludidos na Constituição Federal de 1988 a respeito da obrigatoriedade e da competência do Estado ao fornecimento do ensino médio.

Assim, tal tecnologia possibilita o acesso à educação aqueles que não possuem acesso à escola com tanta facilidade, pois moram em áreas de difícil acesso, distritos, reservas extrativistas, assentamentos de reforma agrária e comunidades indígenas que vivem às margens dos rios, o que efetiva o conceito de universalização da educação.

Acredita-se que este trabalho possa ampliar as pesquisas sobre $\circ$ tema, possibilitando compreender os processos que permeiam o EMMTEC no Estado de Rondônia no período, além de contribuir, a partir dos resultados encontrados na pesquisa, com a comunidade acadêmica e a sociedade em geral, tendo em vista a utilização desse referencial teórico para embasar outras pesquisas, bem como sua utilização na formulação de políticas públicas educacionais de qualidade.

Olhar de professor, Ponta Grossa, v. 24, p. I-20, e-I5I48.003, 2021. 


\section{Referências}

AGUIAR, L. Ser e fazer-se docente no ensino médio mediado por tecnologia: o caso do professor presencial de Rondônia. 2018. Dissertação (Mestrado Profissional em Gestão e Avaliação da Educação Pública) - Universidade Federal de Juiz de Fora, Juiz de Fora, 2018.

ALVES, L. Educação a distância: conceitos e história no Brasil e no mundo. Revista Brasileira de Aprendizagem Aberta e a Distância (RBAAD), v. I0, p. 91, $201 \mathrm{l}$.

<https://doi.org/l0.17/43/rbaad.v10i0.235>. Disponível em: Acesso em: I3 ago. 2019.

BRASIL. Presidência da República. Constituição da República Federativa do Brasil. Brasília, DF, Senado Federal: Centro Gráfico, 1988.

BRASIL. Presidência da República. Decreto $n^{\circ}$ 5.622, de 19 de dezembro de 2005: regulamenta $\circ$ art. 80 da Lei $n^{\circ} 9.394$, de 20 de dezembro de 1996, que estabelece as diretrizes e bases da educação nacional. Brasília, DF, 2005a. Disponível em: http://portal.mec.gov.br/seed/arquivos/pdf/dec_5622.pdf. Acesso em: 27 mai. 2019.

BRASIL. Ministério da Educação e Cultura. Lei de Diretrizes e Bases da Educação Nacional. Brasília, DF, Senado Federal: 2005b. Disponível em: https://www2.senado.leg.br/bdsf/bitstream/handle/id/70320/65.pdf. Acesso em: 25 mai. 2019.

BRASIL. Instituto Nacional de Estudos e Pesquisas Educacionais Anísio Teixeira. Plano Nacional de Educação PNE 2014-2024: linha de base. Brasília, DF: Inep, 20I5. Disponível em: http://portal.inep.gov.br/documents// 86968/485745/Plano+Nacional+de+Educa\%C3\%A7\%C3\%A3o+P $\mathrm{NE}+201$ 4-2024++Linha+de+Base/c2dd0faa-7227-40ee-a520-12c6fc77700f?version=I. I. Acesso em: 08 jun. 2019.

BRASIL. Presidência da República. Lei Complementar n 101 , de 4 de maio de 2000: estabelece normas de finanças públicas voltadas para a responsabilidade na gestão fiscal e dá outras providências. Brasília, DF, 2000. Disponível em:

http://www.planalto.gov.br/ccivil_03/leis/lcp/lcp I0I.htm. Acesso em: I3 ago. 2019.

BRASIL. Presidência da República. Lei no 13.005 de 20I4: aprova o Plano Nacional de Educação PNE. Brasília, DF, 2014. Disponível em: http://www.planalto.gov.br/ccivil_03/_ato20II 20I4/20I4/lei/l/3005.htm. Acesso em: 8 jun. 2019.

BRASIL. Ministério Da Educação. Reestruturação e expansão do ensino médio no Brasil: Gt Interministerial instituído pela Portaria n ${ }^{\circ} \mathrm{I} .189$ de 05 de dezembro de 2007 e Portaria $n^{\circ} 386$ de 25 de março de 2008. Brasília, DF, 2008. Disponível em:

http://portal.mec.gov.br/seb/arquivos/pdf/2008/interministerialresumo2.pdf. Acesso em: 08 jun. 2019.

COSTA, M. L. F.; OLIVEIRA, S. A. G. de. O lugar da educação a distância no plano nacional de educação (20 I I-2020). Teoria e Prática da Educação, v. I6, n. I, p. 97-I I2, 2013.

GERHARDT, T. E.; SILVEIRA, D. T. Métodos de pesquisa. Porto Alegre: Editora UFRGS, 2009.

GERMANO, M. S.; ZUIN, A. L. A. Ensino médio com mediação tecnológica - EMMT: reestruturar para mercantilizar. Revista Praxis Pedagógica, v. I, n. 3, p. 7I-92, 2018.

Olhar de professor, Ponta Grossa, v. 24, p. I-20, e-|5|48.003, 202 I.

Disponível em https://revistas2.uepg.br/index.php/olhardeprofessor 
GIL, A. C. Como elaborar projetos de pesquisa. 4. ed. São Paulo: Atlas, 2002.

IBGE. Instituto Brasileiro de Geografia e Estatísticas. Cidades e estados: Rondônia. 2019.

Disponível em: https://www.ibge.gov.br/cidades-e-estados/ro.html. Acesso em: 20 jun. 2019.

RONDÔNIA. Ministério Público do Estado de Rondônia. Recomendação n. 00 I/2018 -CAOP

Educação. Rondônia: MPRO, 2018. Disponível em: https://www.mpro.mp.br/web/caopeducacao/atribuicoes\#. Acesso em: 8 jun. 2019.

RONDÔNIA. Lei n ${ }^{\circ}$ 3.846, de 4 de julho de 2016: institui o projeto ensino médio com mediação tecnológica no âmbito da Secretaria de Estado de Educação e dá outras providências. Diário Oficial, n. 122. 5 jul. 2016. Disponível em: http://www.diof.ro.gov.br/data/uploads/2016/07/Doe05_07_2016.pdf. Acesso em: 25 mai. 2019.

RONDÔNIA. Secretaria de Estado do Planejamento, Orçamento e Gestão. Lei n⿳ 4.455, de 07 de janeiro de 20 19: estima a receita e fixa a despesa do estado de Rondônia para o exercício financeiro de 2019. Rondônia: SEPOG, 2019b. Disponível em: http://www.sepog.ro.gov.br/Uploads/Arquivos/PDF/LOA/2019/LOA\%20aprovada.pdf. Acesso em: 8 jun. 2019.

RONDÔNIA. Secretaria de Estado do Planejamento, Orçamento e Gestão. Lei orçamentária anual - LOA. SEPOG, 2019c. Disponível em: http://www.sepog.ro.gov.br/Conteudo/Exibir/378. Acesso em: 7 jul. 2019.

RONDÔNIA. Ministério Público do Estado de Rondônia. CAOP educação. Rondônia: MPRO, 2019a. Disponível em: https://www.mpro.mp.br/web/caop-educacao. Acesso em: 8 jun. 2019.

RONDÔNIA. Ministério Público do Estado de Rondônia. Atribuições e competências do caop educação. Rondônia: MPRO, 2020. Disponível educacao/atribuicoes\#. Acesso em: 8 jun. 2019.

em: https://www.mpro.mp.br/web/caop-

RONDÔNIA. Secretaria de Estado da Educação. Plano Estadual de Educação - PEE/RO: 2014 a 2024. 2014. Disponível em:

http://www.avaliacaoinstitucional.unir.br/uploads/87878787/5592_2014_pee_seduc.fee_ro_(plano_es tadual_de_educacao_de_rondonia_de_2014_a_2024).pdf. Acesso em: I2 jun. 2019.

RONDÔNIA. Superintendência de Assuntos Estratégicos. Plano estratégico 2016-2020. Porto Velho: SEAE, 2016.

RONDÔNIA. Secretaria de Estado de Assuntos Estratégicos. Rondônia de oportunidades: Plano Estratégico 2013 - 2018. Porto Velho: SEAE, 2013. Disponível em:

http://www.rondonia.ro.gov.br/publicacao/plano-estrategico-20I3-20I8-rondonia-de- oportunidades/. Acesso em: 7 jul. 2019.

SANO, H.; FILHO, M. J. F. M. As técnicas de avaliação da eficiência, eficácia e efetividade na gestão pública e sua relevância para o desenvolvimento social e das ações públicas. Desenvolvimento em questão, v. II, n. 22, p. 35-61, 2013.

Recebido em: 13 de abril de 2020.

Olhar de professor, Ponta Grossa, v. 24, p. I-20, e-I5I48.003, 2021.

Disponível em https://revistas2.uepg.br/index.php/olhardeprofessor 
Versão corrigida recebida em: 04 de agosto de 2020.

Aceito em: 07 de setembro de 2020.

Publicado online em: 05 de março de 202I.

(a) $\underset{10}{\mathrm{Ix}}$

Olhar de professor, Ponta Grossa, v. 24, p. I-20, e-15I48.003, 2021.

Disponível em https://revistas2.uepg.br/index.php/olhardeprofessor 